\title{
Endometrium, serviks ve larinks kanserlerinin yoğunluk ayarlı radyoterapi tekniğinde doz homojenite indeksinin kantitatif olarak değerlendirilmesi ve homojenite indeks değerlerinin karşılaştırılması
}

\author{
Ebru CANTÜRK ${ }^{1, ~ *}$, Gözde TOPGÜL ${ }^{1}$, Orhan GÜRLER ${ }^{2}$, Sema TUNÇ ${ }^{3}$, Candan DEMİRöZ \\ ABAKAY $^{3}$, Meral KURT ${ }^{3}$, Sibel KAHRAMAN ÇETINTAS ${ }^{3}$ \\ ${ }^{l}$ Uludağ Üniversitesi, Sağlık Bilimleri Enstitüsü, Sağlık Fiziği Bölümü, Bursa-TURKEY \\ ${ }^{2}$ Uludağ Üniversitesi, Fen Edebiyat Fakültesi Fizik Bölümü, Bursa-TURKEY \\ ${ }^{3}$ Radyasyon Onkolojisi Anabilim Dalı, Tip Fakültesi, Uludağ Üniversitesi, 16059 Bursa, Turkey \\ Gelis Tarihi (Recived Date): 21.08 .2017 \\ Kabul Tarihi (Accepted Date): 06.12.2017
}

Özet

Bu araştırmada amaç; endometrium, serviks ve larinks kanserlerinin yoğunluk ayarlı radyoterapi (YART) tekniğinde 6 farklı homojenite indeks formülleri kullanılarak hesaplanan değerleri karşılaştırmak ve doz homojenitesi için en iyi homojenite indeksini belirlemektir.

Bu callşmada, ELEKTA SYNERGY lineer hizlandirıcısinda 6 MV foton enerjisi ile dinamik Multi Lif Kolimatör (dMLC) yoğunluk ayarl radyoterapi (YART) tedavi tekniği ile tedavi edilen 30 hastanin (10 endometrium, 10 serviks, 10 larinks) 6 farkl formülle hesaplanan homojenite indeks sonuçları değerlendirilmişstir. Yoğunluk ayarlı radyoterapi (YART) planları MONACO tedavi planlama sisteminde planlanmışıtır. Ayrıca, homojenite indeksini etkileyen faktörler de incelenmişstir. Elde edilen veriler Sosyal Bilimler İçin İstatistik Programı (SPSS) istatistiksel analiz programı yardımıyla analiz edilmişstir.

Anahtar Kelimeler: Homojenite, indeks, YART, doz, monaco.

Comparison of homogeneity indices for quantitative evaluation of dose homogeneity for imrt treatments of endometrium, cervix and larynx cancers

\footnotetext{
Abstract determine the best homogeneity indices for dose homogeneity.

*Ebru CANTÜRK, ebru_canturk@hotmail.com,http://orcid.org/0000-0003-2467-8759

Gözde TOPGÜL, gozdetopgul@gmail.com, http://orcid.org/0000-0003-4504-3648

Orhan GÜRLER, ogurler@uludag.edu.tr, http://orcid.org/0000-0002-8463-3432

Sema TUNÇ, sgozcu@gmail.com, http://orcid.org/0000-0003-4697-8234

Candan DEMIRÖZ ABAKAY, candande@uludag.edu.tr, http://orcid.org/0000-0001-5380-5898

Meral KURT, mkurt@uludag.edu.tr, http://orcid.org/0000-0003-1637-910X

Sibel KAHRAMAN ÇETINTAȘ, skahraman@uludag.edu.tr, http://orcid.org/0000-0002-4483-9284
}

The aim of this study is to compare results that are calculated using 6 different homogeneity index formulae for Intensity Modulated Radiation Therapy (IMRT) in endometrium, cervix and larynx cancers and to

In this study 6 different homogeneity index formulae were evaluated for 30 patients for endometrium, cervix and larynx cancer patients receiving dynamic Multileaf Collimator (dMLC) Intensity Modulated Radiation Therapy (IMRT) treatments on ELEKTA SYNERGY linear accelerator with 6 MV photon beam. Intensity 
Modulated Radiation Therapy (IMRT) plannings were carried out on MONACO treatment planning system. The factors that could effect the homogeneity indices were examined. The data obtained that were analyzed with Statistical Package for the Social Sciences (SPSS) statistical programme.

Keywords: Homogeneity, indices, IMRT, dose, monaco.

\section{Giriş}

Radyoterapi; iyonize radyasyonlar (yüksek enerjili fotonlar ya da hızlandırılmış subatomik partiküller) kullanılarak malign ve benign tümörlerinin tedavisinde, tümörlü hücrelere yüksek doz verilerek tümörü tamamen ortadan kaldırmak ve tümör boyutunu küçültmek amaciyla küratif ve palyatif amaçla yapılan tedavi şeklidir. Bu tedavideki en önemli amaç ise hedef hacimde homojen bir doz dağııımı yakalarken, etraftaki sağlıklı dokuların radyasyondan minimum derecede etkilenmesini sağlamaktır. Radyasyon (ışın tedavisi) yani radyoterapi, birçok kanser hastalıklarının tedavisinde kullanılmaktadır. Cilt kanseri, Baş-boyun kanserleri, Akciğer kanseri, GiS (Gastrointestinal sistem) kanserleri, Prostat, Mesane, Rektum kanserleri ve Jinekolojik Kanserler (Serviks, Endometrium, Vajen ve Vulva)'dır. 3 boyutlu konformal radyoterapi(3B-KRT), Yoğunluk ayarlı radyoterapi (YART), Volümetrik ark terapi(VMAT), Brakiterapi ve Görüntü Kılavuzluğunda Radyoterapi (IGRT) günümüzde kullanılan radyoterapi tedavi teknikleridir. Farklı tedavi teknikleri kullanılarak oluşturulan tedavi planlarıyla tanımlanan dozu hedef hacme verebilmek amaciyla birden fazla tedavi planı oluşturmak mümkündür. Hangi planın hasta için daha uygun olduğuna karar vermek için konvansiyonel radyoterapide genellikle birkaç transvers kesitteki doz dağılımlarını ve minimum tümör dozu, maksimum kritik organ dozları gibi belirli parametrelerin değerlerine bakılır. Radyoterapi tedavi tekniklerinde plan değerlendirilirken sadece bu parametrelere bakılarak karar verilemez. $\mathrm{Bu}$ sebeple, Doz-Volüm Histogramları (DVH), Konformite İndeksi (CI) ve Homojenite İndeksi (HI) gibi parametreler farklı tedavi tekniklerinde yapilan planların değerlendirilmesinde kullanılmaktadır. Her plan hastaya özeldir. Hangi planın daha uygun olduğuna karar vermek için plandaki kritik her noktanın dozlarının karşılaştırılması gerekir. Doz Volüm Histogramları (DVH) bu karşılaştırmayı kolaylaştııır. DVH'ler üç boyutlu doz bilgilerini ilgili her organ için bir eğri olacak biçimde grafiksel olarak özetler.

'Diferansiyel' ve 'Kümülatif' olmak üzere iki tip DVH vardır. Diferansiyel DVH, volümdeki doz farklılığını en düşükten en yükseğe gösterir. Kümülatif DVH, ise spesifik doz almış anatomik yapının volümünü gösterir. Kümülatif DVH'ler, Diferansiyel DVH'ler den daha kullanışlıdır ve daha yaygın kullanılmaktadır. $\quad \mathrm{Bu}$ nedenle $\mathrm{DVH}$ dendiğinde, Kümülatif DVH anlaş1ır[1].

Hedef hacim dozları (CTV, PTV) değerlendirilirken ICRU 62'nin önerdiği Konformite İndeks (CI) tanımı kullanılır. Konformite İndeksi, tedavi edilen hacmin, planlanan hedef hacime oranıdır.

$\mathrm{CI}=\mathrm{TV} / \mathrm{PTV}$ olarak tanımlanır.

Van't Riet ve arkadaşlarına göre[2] ;

$\mathrm{CN}=\frac{T V_{R I}}{T V} \mathbf{x} \frac{T V_{R I}}{V_{R I}}$

$T \boldsymbol{V}_{\boldsymbol{R I}}=$ Hedef hacmi saran referans izodoz

TV=Hedef Hacim

$V_{R I}=$ Referans izodozun Hacmi

$\mathrm{CN}$ 'nin ideal değeri $\mathbf{0}<\mathbf{C N} \leq \mathbf{1}$ değer 1 ise ideal doz dağılımını gösterir.

RTOG protokolleri tarafindan tedavi kalitesini ölçmek için belirlenen bir diğer değer de Homojenite Indeksi (HI) dir. Sadece RTOG protokolü değil aynı zaman da ICRU (International Committee on Radiological Units and Measurements/Uluslararas1 Radyasyon Birimleri Komitesi) protokolü tarafından da PTV dozları değerlendirilirken CI'e ilave olarak HI tanımının da kullanılması önerilmektedir.

Homojenite Indeks değeri belirlenen PTV hacmi için verilen dozun hacim içerisinde ne kadar homojen, eşit oranlarla dağıldığının göstergesidir.

CI ve HI birlikte değerlendirilmelidir. CI 1'e yakın olmalıdır.

Radyasyon onkologları ve medikal fizikçiler, bir planı değerlendirirken klinik, biyolojik, geometrik, dozimetrik ve radyolojik parametreleri ayn anda düşünmek zorundadır; bu da karmaşık ve zaman alıcı bir süreçtir. Bu sebeple; HI, optimum plan için hızlı bir kalite göstergesidir; hedef içindeki doz dağılımı hakkında genel bir bilgi vermekte ve homojenliğin objektif bir ölçüsünü sağlayarak kolaylaştırabilmektedir.

Genellikle radyasyon onkologları aynı hastalar için farklı planlar uygular ve objektif parametrelerin olmaması durumunda ise seçim yapmak zorlaşır. En iyi plan için $\mathrm{HI}$ ile birlikte diğer parametreler de ele alınıp seçilir. 
Radyoterapide sonuçların değerlendirilmesinde, veri değerlendirmesinden bir çıkarım yapılması için oldukça fazla zaman gerekir. Ancak HI gibi tedavi planlama parametreleri bir planın kalitesini belirlemek için zamandan tasarruf sağlarlar.[3]. YART, 3BKRT ve VMAT gibi radyoterapinin farklı tekniklerindeki HI'ni analiz eden birçok çalışmada olduğu gibi bu çalışmada da en uygun (optimal) homojenite indeksi hesaplamalarında kullanılan farklı formüller arasında bir uzlaşmaya varılamamıştır.

Bütün bu değerlendirmeler göz önünde bulundurularak ve yapılan araştırmaları değerlendirip, HI'in önemini kavrayıp, geliştirmek amacıyla bu çalışmada altı farklı homojenite indeksi formülü kullanılarak hesaplamalar yapılmış ve sonuçlar değerlendirilmiştir.

\section{Gereç ve yöntemler}

Endometrium, Serviks ve Larinks tümörleri için tedavi edilen 30 hasta incelenmiştir. Tüm planlar bölümde takip edilen klinik protokole göre oluşturulmuştur. Hedef hacimlerin ve risk altındaki organların tanımlanması için Bilgisayarlı Tomografi (BT) tarama tabanlı radyografik hacim veri seti kullanılmıştır. Gross Tümör Hacim (GTV), Klinik Hedef Hacim (CTV) ve Planlanan Hedef Hacim (PTV) gibi hedef hacimler, Uluslararası Radyasyon Üniteleri ve Ölçümleri Komisyonu (ICRU) 83 numaralı raporda detaylı olarak anlatılmıştır[4]. Tedaviyi gerçekleştiren radyasyon onkologları, hedef hacimleri ve tedavi dozunu belirlemektedir. Elekta Synergy cihazında Monaco Tedavi Planlama Sisteminde (TPS), DMLC YART 5 ALANLI planlar oluşturulmuştur. Bu planlarda dikkat edilen hususlar ise; minimum doz $\% 95$ 'e eşit veya daha fazla ve maksimum doz da tanımlanan dozların \%107'sine eşit veya düşüktür.

Homojenite İndeksi hesaplamak için ise seçilen hedef hacim klinik hedef hacimdir (CTV). İki veya daha fazla hedef hacim bulunduğunda, analiz için en büyük hedef hacim seçilmiştir. Tanımlanan doz farklı tümör yerleşim yerlerine göre; endometrium 50.4 Gy, serviks 59.4 Gy, larinks 63 Gy olarak tanımlanmıştır. Bütün planların doz hacim histogramı (DVH) oluşturulmuş ve kabul edilebilir bir plan elde edinceye kadar medikal fizikçi ve radyasyon onkologları birlikte değerlendirmiştir.

HI'ler aşağıda tanımlanan 6 farklı formül kullanılarak hesaplanmıştır.

$\mathrm{HI}=\mathrm{D}_{\text {maks }} / \mathrm{D}_{\text {min }}$ :

(2)'de; $D_{\text {maks }}$ ve $D_{\text {min }}$ sirasiyla hedef hacimdeki maksimum ve minimum nokta dozlarını temsil eder.
Gerçek minimum ve maksimum dozun hesaplanması ve yüksek doz gradyanı, grid boyutu ve konumlanımı gibi doz hesaplama parametrelerine bağlı olduğundan, eğer yalnızca nokta dozlar göz önünde bulundurulursa dozlar çok yüksek ya da çok düşük olacağından uygulamada gerçek minimum veya maksimum dozunu kullanmak güvenilir değildir. Bir noktadan ziyade hacimdeki maksimum veya minimum dozun $\left(\mathrm{D}_{\% 5}, \mathrm{D}_{\% 95}, \mathrm{D}_{\% 2}\right.$ ve $\mathrm{D}_{\% 98} \mathrm{vb}$.) seçilme nedeni budur [5] .

$\left(\mathbf{D}_{\% 2}-\mathbf{D}_{\% 98}\right) / \mathbf{D}_{\mathbf{P}}$

(3)'de; $\mathrm{D}_{\% 2}$ ve $\mathrm{D}_{\% 98}$ hedef hacmin $\% 2$ 'sine ve $\% 98$ 'ine verilen minimum dozları temsil etmektedir. $\mathrm{D}_{\mathrm{P}}$ ise reçete edilen (önerilen) dozdur $[5,6]$.

$\mathbf{H I}=\mathbf{D}_{\% 5} / \mathbf{D}_{\% 95}$

$\mathrm{D}_{\% 5}$ ve $\mathrm{D}_{\% 95}$ sirasiyla hedef hacmin $\% 5$ 'i ve $\% 95$ 'ine verilen minimum dozlardır [7] .

2, 3, 4 formülleri için ideal değer 1'dir. Bu değer arttıkça plan homojenlikten uzaklaşmaktadır.

$\mathrm{HI}=\left(\mathrm{D}_{\% 5}-\mathrm{D}_{\% 95}\right) / \mathrm{D}_{\mathbf{P}}$

$\mathrm{D}_{\% 5}$ ve $\mathrm{D}_{\% 95}$ sirasiyla hedef hacmin $\% 5$ 'i ve \%95'ine verilen minimum dozlardır. $\mathrm{Dp}$ ise reçete edilen dozdur [8] .

$\mathbf{R T O G}=\mathbf{I}_{\text {maks }} /$ RI;

$I_{\text {maks }}$, PTV alanındaki maksimum doz oranı RI: referans izodoz. Homojenite İndeksini RTOG protokolüne göre yorumladığımızda; HI parametresi 2 dahil 2'den küçük olduğu durumlarda $(\mathrm{HI}<2)$ uygulanan tedavi planının protokole uygun olduğu kabul edilir. HI değeri 2 ile 2.5 arasında olduğunda protokolden minör yani küçük çapta bir sapma olduğu kabul edilir. Ancak bu HI parametresi 2.5 değerini aştığı durumda tedavi planının protokolden maksimum derecede sapmış olduğu kabul edilmektedir. Yapılan tedavi planının homojenlikten uzaklaşmasına rağmen yine de tedavi planının uygulanabilirliği öngörülmüştür. $\mathrm{Bu}$ nedenle Homojenite Index değeri bir başka protokole göre de yorumlanmıştır [9] .

ICRU83 $=\left(D_{\% 2}-D_{\% 98}\right) / D_{\% 50}$

$\mathrm{D}_{\% 2}$ : PTV'nin \%2'sinin aldığ 1 doz, D $\%_{50}$ PTV'nin \%50'sinin aldığ 1 doz, D\%98: PTV'nin \%98'inin aldığı dozdur.

Homojenite Index' ini ICRU 83 protokolüne göre yorumladığımızda; HI'nin 0'a yaklaşması PTV' deki doz dağılımının oldukça homojen olduğunu gösterir. HI değeri 0'dan uzaklaştıkça doz homojenitesi azalmakta bu yüzden yapılan planın tercih edilme 
oranı azalmaktadır.. Bu durumda yapılan plan tekrar gözden geçirilmeli, yapılabilecek en iyi plan yapılmalı ve en uygun HI değeri elde edilmelidir. Aksi durumda hastaya uygulanan tedavinin yararından çok zararı olacaktır [9] .

Daha sonra hastalar tanımlanan doza (prescription) göre 3, hedef hacme (CTV) göre 3, hedefin bulunduğu yere yani lokasyona göre 3 gruba ayrılmıştır. Bu 9 farklı grupla sonuçlanmıştır. Her bir grup için ortalama homojenite indeksi (HI) tüm formüllerle hesaplanmıştır. Veriler daha sonra HI ile reçete edilen doz, hedef hacim ve vücuttaki hedefin konumu gibi çeşitli parametreler arasındaki ilişkiyi bulmak için analiz edildi. 6 farklı HI formülleri kullanılarak elde edilen veriler Microsoft Office Word yazılımı programı aracılığıyla tablolarla düzenlenmiş ve SPSS 22 istatistik yazılımı kullanılarak HI'nin ortalama ve medyan değerleri hesaplanmıştır. Pearsons Chi-Square testi (SPSS 22) ise 6 farklı formül kullanılarak hesaplanan HI değerlerinin ortalama değerleri ile tanımlanan doz, hedef hacme ve hedefin konumu arasındaki ilişkiyi test etmek için kullanıldı. Elde edilen sonuçlar ise Tablo 2, 3, 4 ve 5'te gösterildi. Aynı test, Tablo 3, 4 ve 5 'te tek bir formülü kullanarak her bir grup için ayrı ayrı gerçekleştirildi.

Verilerin son analizinde 10 erkek ve 20 kadın vardır. $\mathrm{Bu}$ hastaların \%33.3 endometrium, \%33.3 serviks, \%33.3 larinks tümörlerine sahip olan hastalar radyasyon tedavisi görmüştürler. Hastaların ayrıntılı tanımlayıcı verileri Tablo 1'de sunulmuştur.

Tablo 1. Hastaların karakteristi özellikleri

\begin{tabular}{cc}
\hline Toplam Hasta Sayısı & \\
\hline Kadın & $\% 33.3$ \\
Erkek & $\% 66.6$ \\
\hline \multicolumn{2}{c}{ Tedavi } \\
\hline Endometrium & $\% 33.3$ \\
Serviks & $\% 33.3$ \\
Larinks & $\% 33.3$ \\
\hline
\end{tabular}

\section{Bulgular}

HI'nin maksimum, minimum, ortalama ve medyan değerleri, Tablo 2'de gösterildiği gibi, tüm hastalar için farklı formül (2, 3, 4, 5, 6 ve 7) kullanarak topluca hesaplandı. Formüllerle hepsi tüm hastalar için ayrı ayrı hesaplandı.

Tablo 2. Farklı formüllerle hesaplanan HI değerleri

\begin{tabular}{cccccc}
\hline Eşitlikler & Hasta sayıları & Maksimum & Minimum & Ortalama & Medyan \\
\hline $\mathbf{2}$ & 30 & 1.71 & 1.05 & 1.23 & 1.18 \\
$\mathbf{3}$ & 30 & 0.09 & 0.03 & 0.05 & 0.06 \\
$\mathbf{4}$ & 30 & 1.07 & 1.02 & 1.04 & 1.04 \\
$\mathbf{5}$ & 30 & 0.07 & 0.04 & 0.05 & 0.05 \\
$\mathbf{6}$ & 30 & 1.07 & 1.05 & 1.06 & 1.06 \\
$\mathbf{7}$ & 30 & 0.09 & 0.02 & 0.05 & 0.06 \\
\hline
\end{tabular}

Tablo 3. Tanımlanan doza göre HI değerleri

\begin{tabular}{cccccccc}
\hline Tanımlanan doz & Hasta Sayısı & Eşitlik 2 & Eşitlik 3 & Eşitlik 4 & Eşitlik 5 & Eşitlik 6 & Eşitlik 7 \\
\hline $\mathbf{5 0 4 0}$ & 10 & 1.38 & 0.07 & 1.05 & 0.05 & 1.06 & 0.07 \\
$\mathbf{5 9 4 0}$ & 10 & 1.17 & 0.06 & 1.04 & 0.04 & 1.06 & 0.05 \\
$\mathbf{6 3 0 0}$ & 10 & 1.14 & 0.03 & 1.02 & 0.02 & 1.05 & 0.02 \\
\hline
\end{tabular}

HI analizinde, bütün formüllerde ve bütün bölgeler içinde kıyasladığımızda; 2 formülüyle hesaplanan HI değerleri 4 ve 6 formülleriyle hesaplanan HI değerlerine göre daha yüksek HI değerlerine sahiptir. Ayrıca yine bütün bölgeler içinde 3 formülüyle hesaplanan HI değerleri; 5 ve ICRU 83 raporu tarafından hazırlanan 6 formülleriyle hesaplanan HI değerlerine göre daha yüksek HI değerlerine sahiptir.

Tablo 2'ye göre minimum HI (en iyi homojenlik) tüm formüllerle incelendiğinde, aynı hastada bu değeri gösterdi. Hasta, 23.465 cc'lik hacmi için 6300 cGy reçeteli dozda bir larinks (baş-boyun) hastasıdır. Bu, farklı formüller arasındaki uyuşmayı gösterir. Ancak aynı eğilim, HI'nin maksimum değerlerini analiz ederken gözlemlenemedi. HI'nin maksimum değeri, her bir formüle göre farklı hastada görülmüştür.
Doz reçetesi 5040 cGy ile 6300 cGy arasında değişmektedir. Genel ortalama ve medyan reçeteli doz sirasiyla 5760cGy ve 5940 cGy idi. Hastalar reçete edilen doza göre 3 gruba ayrıldı ve her bir grup için ortalama HI, bütün formüller kullanılarak hesaplandı. Sonuçtaki HI değerleri Tablo 3'te gösterildi.

Tablo 3'e göz atarsak en yüksek doz, yani tüm formüllerde $6300 \mathrm{cGy}$ olan HI grubunun en düşük değerleri (en iyi homojenlik) görülmüştür. Benzer şekilde, en yüksek HI değerleri 5040 cGy olan grupta görülmüştür. Farklı formüllerle hesaplama yapılsa da benzer sonuçlar gözlenmiştir. Bu verilere göre, tanımlanan doz değeri arttıkça homojenite indeksi değeri azalmaktadır yani homojenliğin daha iyi olduğu gözlenmektedir. 
Tablo 4: HI'nin hedef hacme göre değerleri

\begin{tabular}{cccccccc}
\hline Hedef Hacim (cc) & Toplam Hasta Sayısı & Eşitlik 2 & Eşitlik 3 & Eşitlik 4 & Eşitlik 5 & Eşitlik 6 & Eşitlik 7 \\
\hline $\mathbf{1 0 0}$ & 10 & 1.14 & 0.03 & 1.02 & 0.05 & 1.06 & 0.07 \\
$\mathbf{1 0 1} \leq \mathbf{7 0 0}$ & 11 & 1.29 & 0.06 & 1.04 & 0.04 & 1.06 & 0.06 \\
$\mathbf{7 0 0} \leq \mathbf{1 3 0 0}$ & 6 & 1.24 & 0.06 & 1.04 & 0.04 & 1.06 & 0.06 \\
\hline
\end{tabular}

Tablo 5: Hedefin konumuna göre HI değerleri

\begin{tabular}{cccccccc}
\hline Konum & Toplam sayı=30 & Eşitlik 2 & Eşitlik 3 & Eşitlik 4 & Eşitlik 5 & Eşitlik 6 & Eşitlik 7 \\
\hline Endometrium & 10 & 1.38 & 0.07 & 1.05 & 0.05 & 1.06 & 0.07 \\
Serviks & 10 & 1.17 & 0.06 & 1.04 & 0.04 & 1.06 & 0.05 \\
Larinks & 10 & 1.14 & 0.03 & 1.02 & 0.02 & 1.05 & 0.02 \\
\hline
\end{tabular}

Tablo 4 ayrıntılı olarak analiz edildiğinde, tüm formüllere göre HI'nin en düşük değerleri (en iyi homojenlik) en düşük hacme, yani $100 \mathrm{cc}$ veya daha düşük olan grupta gözlenmesine rağmen, son iki grupta (700 cc ve 700cc'den daha fazla cc) en yüksek HI, formül 6 haricindeki tüm formüllerde görülmüştür. Bu formül 6 dışındaki farklı formüller arasında uyuşma olduğunu gösterir. $\mathrm{Bu}$ gözlem HI'nin hedef hacim arttıkça kötüleşme yönünde eğilim olduğunu göstermektedir.

Vücuttaki tümör yerleşimine göre hastalar gruplara ayrıldığında hasta sayıları endometriumda (\%33.3), serviks (\%33.3) ve larinks (\%33.3)'tür. Hastaların tümör yerleşimine göre dağılımı ve HI'nın ortalama değerleri farklı formüllerle kesin olarak Tablo 5'te gösterilmiştir.

Endometrium hastalarında bulunan HI değerlerinin en yüksek değerlerinin sahip olduğu gözlenmiştir. Buna karşıllk en iyi homojenite indeksi, larenks (formüllerin hepsi) gözlendi. Serviks hastalarında ise HI değerleri ortalama değerler aldı. HI hesaplamalarında kullanılan çeşitli formüller arasındaki uyuşma seviyesini göstermektedir.

\section{Tartışma ve sonuç}

CI ve HI, hedef hacimdeki doz dağılımı için kullanılan en önemli parametrelerdir. Bundan dolayı, her iki parametre yapılan tedavi planlarını değerlendirmek için kullanılmaktadırlar. Birçok çalışma CI ve CI'ni etkileyen faktörler üzerine odaklanmış olmalarına rağmen, HI ve HI'ni etkileyen faktörler üzerine fazla çalışma yapılmamıştır. HI hedef hacimdeki doz dağılımı modelinin iyi bir göstergesi olduğundan ve etkileyen faktörlerin neler olduğunun netleşmemesi sebebiyle, bu çalışmada HI ve HI'ni etkileyen faktörler üzerinde araştırma yapılmıştır. Knoss ve ark., (Knoss et al) Konformite İndeksi (CI) değerlendirmelerinde, pelvik tümörlü olgularda akciğer ve ileri meme kanseri vakalarına kıyasla tümör yerleşimi ve CI değerleri arasında pozitif yönde korelasyon (ilişki) bulmuşlardır. Aynı yazarlar meme kanseri grubunda PTV hacminde artış ile CI değeri arasında yine pozitif yönde korelasyon bulmalarına rağmen, tüm hastalar birlikte değerlendirildiğinde CI ve PTV hacmi arasında böyle bir korelasyon bulamadıklarını belirtmişlerdir [10]. Benzer şekilde, $\mathrm{Wu}$ ve ark., (Wu et al) Özefagus ve akciğer kanserli olgularda, nazofaringeal ve prostat kanserlerine göre CI ve tümör yerleşimi arasında pozitif yönde korelasyon olduğunu bulmuşlardır [11]. Bizim çalışmamızı da tümörün yerleşim yerine göre değerlendirdiğimizde; en yüksek HI değerleri (yani kötü homojenlik) endometrium hastalarında görülürken; en düşük homojenite indeks değerleri (yani iyi homojenite) larinks hastalarında görülmüştür.

Bir başka çalışmada, konformite indeksinin hedef hacim boyutu ve şekli ile ilişkisini değerlendirmek için Wu ve ark. (Wu et al) hem hacim hem de şekil karmaşıklığının konformite değerleri üzerinde önemli etkileri olabileceğini bulmuştur. Konformite indekslerinin, daha büyük hacimler veya daha basit şekiller olanlara kıyasla, daha küçük veya daha karmaşık hedefler için daha düşük değerlere sahip olma eğiliminde olduklarını buldular [12]. Yapılan çalışmada ise CI indeks yerine HI değerleri ve etkileyen faktörler üzerine yoğunlaşıldı. Hacim boyutuna göre HI değerlerini incelediğimizde ise; HI'nin en düşük değerleri (en iyi homojenlik) en düşük hacme sahip olan hasta grubunda gözlenmiştir.

Bu çalışmada, formül 2 ve formül 3 kullanılarak hesaplanan HI, sırasiyla formül 4, formül 5, formül 6 ve formül 7 kullanılarak hesaplananlara kıyasla, tüm bölgeler için daha yüksek değerler gösterdi. Ayrıca; 6 ve 7 kullanilarak hesaplanan HI, 4 ve 5 kullanılarak hesaplananlara göre tüm bölgeler için daha yüksek değerler gösterdi. Dolayısıyla, plan değerlendirmesinde 4 ve 5 kullanılması tercih edilir. $\mathrm{Bu}$, Kataria ve arkadaşlarının 2012 sonuçlarına uygundur (Kataria ve ark. $\mathrm{D}_{\% 2}$ yerine $\mathrm{D}_{\% 1}$ kullanılmıştır) [9].

Homojenite indeksi tedavi planları değerlendirilmesinde hızlı ve objektif olsa da tek değerlendirme aracı olarak kullanılmamalıdır. Homojenite indeksi, kritik organlar ve hedef doku 
içinde minimum, maksimum doz alan yerler gibi önemli verileri bize sağlamadığı için doz dağılımı ayrıntılı olarak gözden geçirilmeli, kesin sonuç için diğer tüm araçların da olduğu bir araçlar seti kullanılmalıdır.

Bu çalışmada HI'nin en düşük değeri; en yüksek doz olan grupta bulunmuştur. HI, hedef hacim düştükçe

\section{Kaynaklar}

[1] Bilge, H., Planların Değerlendirilmesi, in Çetingöz, R., Garipağaoğlu, M., Uzal, C., Bilge, H., Gökçe, Ş.Ç., Özyiğit, G. ve Yıldız, O.G., Temel ve Klinik Radyoterapi, Hürriyet Matbaa, 82-83, İzmir, (2013).

[2] Van't ,Riet, A., Mak, A.C., Moerland, M.A.ve Elders, L.H., A conformation number to quantify the degree of conformality in brachytherapy and external beamm irradiation: Application to the prostate. International Journal Radiation Oncology Biology Physics.37, 731-736 (1997).

[3] Yu, C., Jozsef, G., Apuzzo, M.L.ve Petrovich, Z., Dosimetric comparison of cyberKnife with other radiosurgical modalities for an ellipsoidal target. Neurosurgery.53, 1155-62.discussion 1162 1163 (2003).

[4] ICRU83, Prescribing,Recording and Reporting İntensity modulated Photon Beam Therapy, IMRT, ICRU, (2010).

[5] Kataria, T., Sharma, K., Subramani, V., Karrthick, K.P. ve Bisht, S.S., Homogeneity Index: An objevtice tool for assessment of conformal radiation treatments. Journal Medical Physics, 37, 4, 207-213 (2012).

[6] Yoon, M., Park, S.Y., Shin, D., Lee, S.B., Pyo, H.R., Kim, D.Y. ve Cho, K.H., A new homogeneity index based on statistical analysis of the dose-volume histogram. Journal of Applied Clinical Medical Physics, 8, 2, 9-17, (2007).

[7] Semerenko, V.A., Reitz, B., Day, E., Qi, X.S., Miften, M. ve Li, X.A., Evaluation of a azalmaktadır. Endometrium tümörlü hastalarda kompleks geometrik yapıya sahip olduklarından dolayı en yüksek homojenite indeks değerlerini göstermiştir. Daha homojen doz dağılımı elde etmenin yolu özetle; tanımlanan dozun yüksek olması, dozun küçük bir hacme uygulanması ve hedef hacmin olabildiğince basit bir geometride olmasidir.

[8] Wu, Q., Mohan, R., Morris, M., Lauve, A. ve Schmidt-Ullrich, R., Simultaneous integrated boost intensity-modulated radiotherapy for locally advanced head-and-neck squamous cell carcinomas: Dosimetric results. International Journal Radiation Oncology Biology Physics, 26, 573-585(2003).

[9] Çelik, Z., Üç boyutlu konformal radyoterapide conformity index (CI), homogeneity index (HI) ve quality of coverage (QC) parametrelerinin hesaplanmas1 ve hesaplanan değerlerin karşılaştırılması, Yükseklisans Tezi, Yıldırım Beyazıt Üniversitesi, Ankara, (2015).

[10] Knoss, T., Kristensen, I. ve Nilsson, P., Volumetric and dosimetric evaluation of radiation treatment plans: Radiation conformity index. International Journal Radiation Oncology Biology Physics,42, 1169-1176 (1998).

[11] Wu, V.W., Kwong, D.L. ve Sham, J.S., Target dose conformity in 3-dimensional conformal radiotherapy and intensity modulated radiotherapy. International Journal Radiation Oncology Biology Physics,71, 201-206 (2004).

[12] Wu, Q.R., Wessels, B.W., Einstein, D.B., Maciaunas, R.J., Kim, E.Y. ve Kinsella, T.J., Quality of coverage: Conformity measures for stereotactic Radiosurgery. Journal Applied Clinical Medical Physics, 4, 374381 (2003). 